\title{
Numerical Simulation of Mining-Induced Stress Evolution and Fault Slip Behavior in Deep Mining
}

\author{
Zhenhua Jiao $\mathbb{D}$, Lei Wang, Ming Zhang $\mathbb{D}$, and Jiong Wang \\ State Key Laboratory of Mining Response and Disaster Prevention and Control in Deep Coal Mines, \\ Anhui University of Science and Technology, Huainan, Anhui 232001, China \\ Correspondence should be addressed to Zhenhua Jiao; zhjiao@aust.edu.cn
}

Received 12 April 2021; Revised 11 June 2021; Accepted 28 June 2021; Published 13 July 2021

Academic Editor: Xianjie Hao

Copyright (C) 2021 Zhenhua Jiao et al. This is an open access article distributed under the Creative Commons Attribution License, which permits unrestricted use, distribution, and reproduction in any medium, provided the original work is properly cited.

The ground pressure distributes significant variation in underground mining near fault. Fault reactivation is an important factor to induce the rock burst. Therefore, characterizing geological settings in mining areas by the geological information can improve the accuracy of simulation. To investigate the characteristic of mining stress evolution and reactivation of the F16 reverse fault during the retreat Mining-Induced s in Yima coalfield, a three-dimensional digital elevation model based on GIS platform was applied. The 3D geological model includes three working faces, and F16 fault was constructed by AutoCAD software. Then, the 3D geological model was imported into the $\mathrm{FLAC}^{3 \mathrm{D}}$ code to simulate the potential of mining-induced fault reactivation. The simulation results illustrate that the footwall of F16 fault is a high stress concentration area. Affected by F16 fault and the huge thick gravel rock in the roof, the coal seam near the fault accumulates a large amount of elastic strain energy, which increases the potential of rock burst hazards in the process of mining.

\section{Introduction}

With the continuous increase of the depth and intensity of coal mining, the mining engineering layout tends to be complicated and the number of deep mines keeps increasing in China [1]. Rock burst is one of the most hazardous phenomena that accumulates huge elastic energy in surrounding rock and releases instantaneously in the process of mining, which poses a great threat to the safety of personnel and equipment in coal mine. Faults are widely distributed in coal measure strata. In the process of coal seam mining, hidden geological structures such as faults are often encountered. Overburden movement and mining-induced stress distribution show significant variation when the working face in mining is near fault. The considerable field practice shows that deep mining near fault is able to easily induce rock burst and mine earthquakes, and the frequency and degree of damage are significantly increased [2-5]. The conflict between coal mining and safety production is prominent in deep mining near fault. How to effectively prevent rock burst is an urgent problem to be solved in deep mining. Thus, studying the law of fault activation induced by mining disturbance has great significance on disaster prevention.

Although a lot of research has been done on the mechanism of rock burst, it is still unable to accurately predict the specific time and location of rock burst event. The most effective measure is to optimize the design of mining method and mining sequence. At the early stage of coal seam mining, the evaluation of rock burst hazard in the mining area is carried out to define the potential rock burst area and the corresponding risk degree, which can provide a basis for the monitoring and prevention of rock burst in the mining process. At present, the commonly used methods of evaluation of rock burst hazard include the comprehensive index method, which combines the actual geological and mining technical conditions of the mining area and the influence weights of various factors, to evaluate the rock burst risk. According to the stress state and the properties of coal and rock mass, there is a possibility of index diagnosis method of rock burst, combined with coal and rock mass, geological structure, overburden structure, and other factors of coupling evaluation method [6-11]. These methods can assess 
the rock burst hazard of mining area from a macroscopic perspective, but they do not consider the influence of mining disturbance and cannot realize the dynamic assessment of the rock burst risk accompanied by the mining changes.

By means of numerical simulation, the evolution behavior of mining-induced stress under different mining conditions is analyzed, and rock burst area can be divided. Numerical simulation is widely used because it is easy to operate and can predict the rock burst hazard before the implementation of mining projects. However, most of the existing numerical simulation studies on coal seam mining have been properly simplified, instead of using actual stratigraphic data to construct three-dimensional models, which makes the simulation results unable to accurately distribute the ground pressure of coal mining affected by the geological factors.

Numerical simulation technology based on 3D fine geological modeling uses actual stratigraphic data to construct 3D models, which is widely used in oil and gas storage, water conservancy, slope, and open pit mining engineering $[12,13]$. However, it is seldom used in the analysis of ground pressure distribution in underground coal mining. In this study, the geological mining conditions of No. 21 mining area of Qianqiu mine in Yima coalfield are taken as the engineering background, and the numerical simulation research based on fine modeling is carried out to analyze the mining-induced stress evolution and fault slip behavior during mining approaching to F16 fault, and the dynamic rock burst risk regionalization was further discussed. It can provide a theoretical basis for the deployment design of deep mining near fault.

\section{Engineering Background}

2.1. Geological Characteristics of F16 Fault. F16 fault, a nearly EW compression-shear reverse fault, is located in the south of the Yima coalfield. F16 fault was formed under huge compaction environment. F16 fault traverses five coal mines, including Changcun mine, Yuejin mine, Qianqiu mine, Gengcun mine, and Yangcun mine. F16 is a part of Sanmenxia-Pingyu Fault. It extends approximately $45 \mathrm{~km}$ along nearly EW and extends to the south from east. The dip angle of its shallow part is $75^{\circ}$, and that of the deep part is $15^{\circ}$ to $35^{\circ}$. There is 50 to $450 \mathrm{~m}$ in the fault throw, extending $24 \mathrm{~km}$ in length and $2 \mathrm{~km}$ in width along Yima coalfield, which constitutes the mine's southern natural boundary. Geological survey indicates that there are about $4.638 \times 10^{7}$ tons of coal reserved in the vicinity of F16 fault and recoverable reserve of $2.738 \times 10^{7}$ tons.

F16 fault is in a high horizontal tectonic stress environment, and at the same time affected by the mining disturbance of each mine, the superposition of two effects lead to fault activation frequently. Fault activation can be caused by tectonic stress nappe. But the activation cycle is long, at least for decades. It is concluded that the main factor of fault activation is coal mining. Statistics show that among the 107 cases of rock bursts, there are only 8 cases that fall in the area, which is $1000 \mathrm{~m}$ or farther away from the F16 fault with a mining area more than $50 \mathrm{~km}^{2}$. For the mining areas, the range of $6 \mathrm{~km}^{2}$ is 500 to $1000 \mathrm{~m}$ away from $\mathrm{F} 16$ fault. Rock bursts occurred 48 times. For the mining area of $3 \mathrm{~km}^{2}$, where the distance toward the fault is less than $500 \mathrm{~m}$, rock bursts occurred 51 times $[14,15]$. Consequently, the distance of mining area between the F16 fault and the risk of rock bursts is highly correlated in an inverse correlation.

2.2. Working Face Mining History. The average mining depth of the No. 21 mining area in Qianqiu mine is $800 \mathrm{~m}$. The No. 2 coal seam thickness is $23 \mathrm{~m}$, and the dip angle of coal seam is $10-14^{\circ}$. The working face is fully mechanized caving mining, and the roof is managed by full caving method. The immediate roof of the coal seam is $4.4-42.2 \mathrm{~m}$ thick mudstone and $0-27 \mathrm{~m}$ thick sandstone. The main roof of coal seam is conglomerate rock with average thickness of $550 \mathrm{~m}$. The mining successively sequence is No. 21181 working face, No. 21201 working face, and No. 21221 working face in No. 21 mining area, gradually to the deep mining and near the F16 fault. The mining layout of the No. 21 mining area in Qianqiu mine is shown in Figure 1. Geological profile of the west wing of the No. 21 mining area of Qianqiu mine is shown in Figure 2.

The complex geology and mining conditions in the west wing of No. 21 mining area lead to the frequent occurrence of rock bursts and serious damage in the process of coal seam mining, such as the " 6.5 " accident of 21201 working face and the " 11.3 " accident of 21221 working face, resulting in heavy casualties and huge economic losses. The cross section of the roadway shrank instantaneously, the partial cross section became less than $1 \mathrm{~m}^{2}$, the coal seam had a dull sound before rock burst, and the gas concentration exceeded the limit after rock burst [16].

\section{Construction of the 3D Numerical Model}

Numerical calculation has obvious characteristics of quantification, repeatability, and economy, so it is widely used in ground pressure distribution analysis. The calculated results can make assessment of rock burst risk and also provide basic information or basis for other methods. At the same time, it can better reflect the actual situation of the project if it is supplemented by on-site monitoring.

The numerical analysis method based on refined modeling includes the following aspects: determination of engineering geological conditions and in situ stress state, construction of refined numerical model reflecting actual stratum data, selection of mechanical model and surrounding rock mechanical parameters, excavation and support according to mining design, analysis of simulation results after numerical calculation, combined with on-site mine pressure behavior characteristics and various types of rock mass monitoring information, and assessment of rock burst risk in mining areas.

3.1. Construction of the Numerical Model. Based on AutoCAD platform, a 3D geological model was constructed by using spatial sequence profile and DEM hybrid method [17]. The flow chart of generation of $3 \mathrm{D}$ geological model is shown 


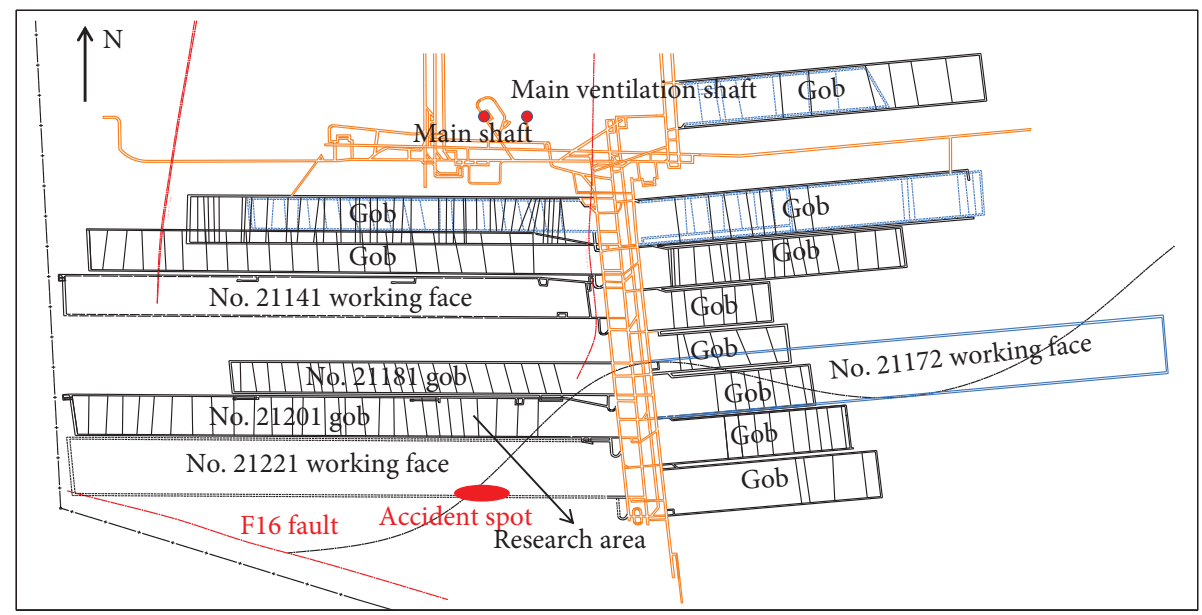

FIgURE 1: Mining layout of the No. 21 mining area in Qianqiu mine.

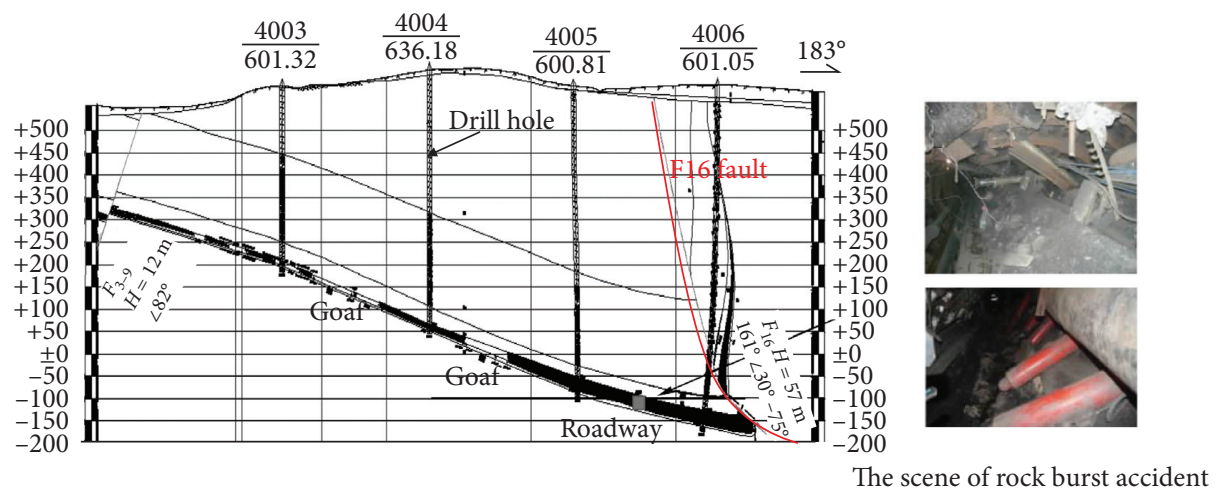

FIgURE 2: Geological profile of the west wing of the No. 21 mining area.

in Figure 3. Firstly, the borehole information, geological profile, and floor contour data are extracted and summarized. The relationship and regularity between the existing data are analyzed. Secondly, the initial data obtained are processed according to certain mathematical methods in order to increase the amount of data. The roof strata, coal seam, and floor are successively constructed to form a complete stratum model. Finally, through a certain optimization combination, the spatial geometry of the orebody and geological structure can be reflected realistically, and the interconnection between the surfaces can form a three-dimensional model.

The construction process of $3 \mathrm{D}$ geological model is shown in Figure 4. ANSYS software is used to generate 3D point line model, and then the point and line model is transformed into three-dimensional model, and the mesh is divided through the ANSYS-FLAC3D transform program to import the three-dimensional entity model into FLAC3D software. As shown in Figure 5, the final numerical model (length $\times$ width $\times$ height) is configured at the size of $1150 \times 1198 \times 979 \mathrm{~m}$. There are 264,580 nodes and 622,410 cells.

The $+X$ direction is the mining direction of the working face, $+Y$ is the dip direction of the working face, $+Z$ direction is vertical to the direction of the model. Working faces are arranged along the dip direction successively, among which the No. 21221 working face is the closest to the F16 fault. The upper bound of the model $Z$ is free, and the upper boundary is the surface. The vertical model is fixed at the bottom, and the horizontal displacement of the side boundary in $X$ - and $Y$-directions is limited.

3.2. In Situ Stress Inversion. The in situ stress in the depth of 700 meters in Qianqiu mine is measured by the method of hydraulic fracturing. The in situ stress distribution is shown in Table 1 [18].

From the table, it can be seen that the stress field type is generally $\sigma_{H}>\sigma_{V}>\sigma_{h}$. Tectonic stress is the main stress in the stress field of mining area. Using in situ stress data, we can calculate the gradient at different location and gradient value. In general, the gradient constraint is applied to the boundary of the model, and then the stress field of the model is generated by the model self-weight stress. The directions of maximum principal stress and the minimum principal stress on the $X-Y$-plane are coincident with the $X$ - and $Y$ axes, and the $Z$-axis coincides with the vertical stress. The existence of the shear stress is neglected. 


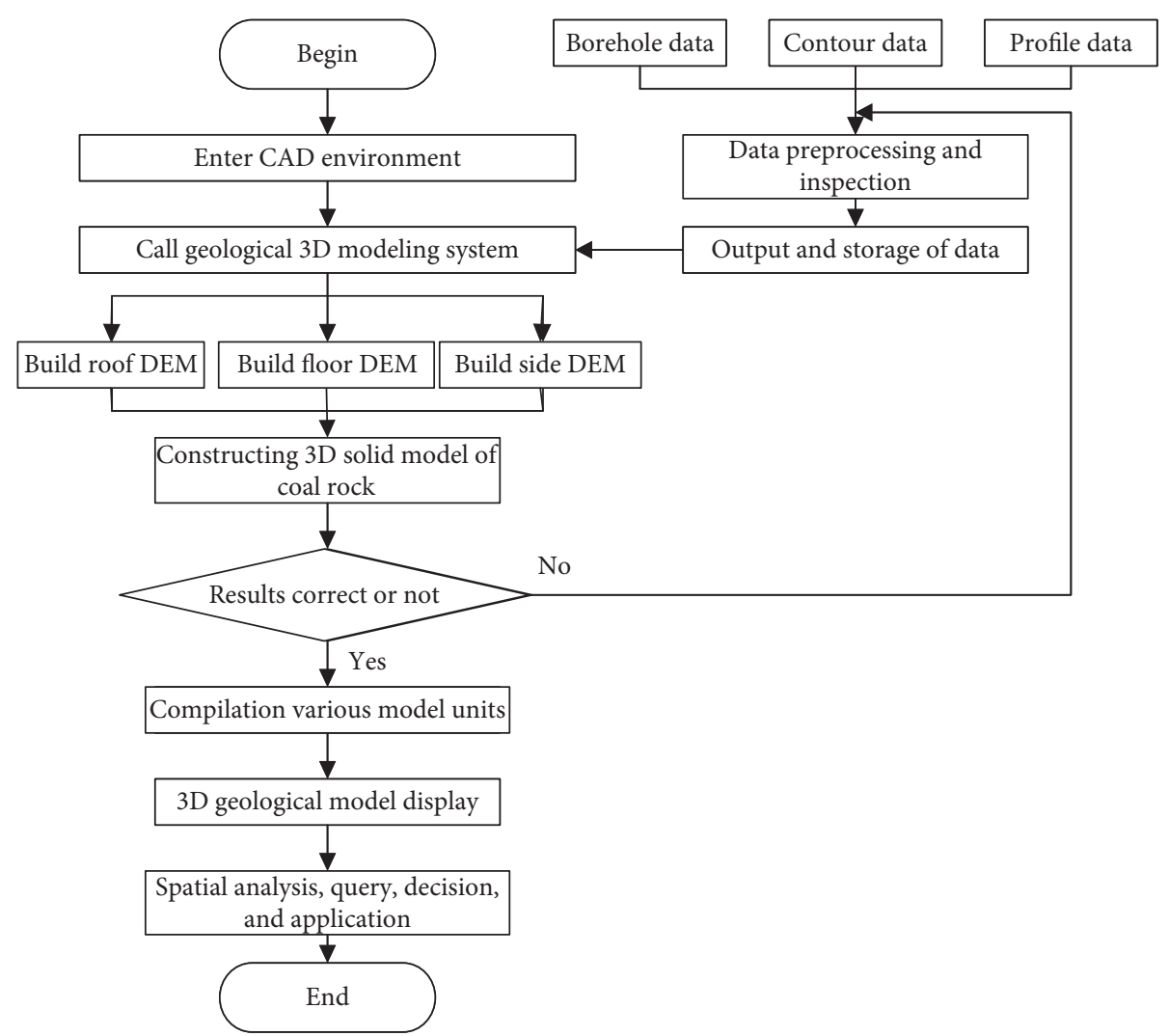

FIGURE 3: Flow chart of generation of the 3D geological model.

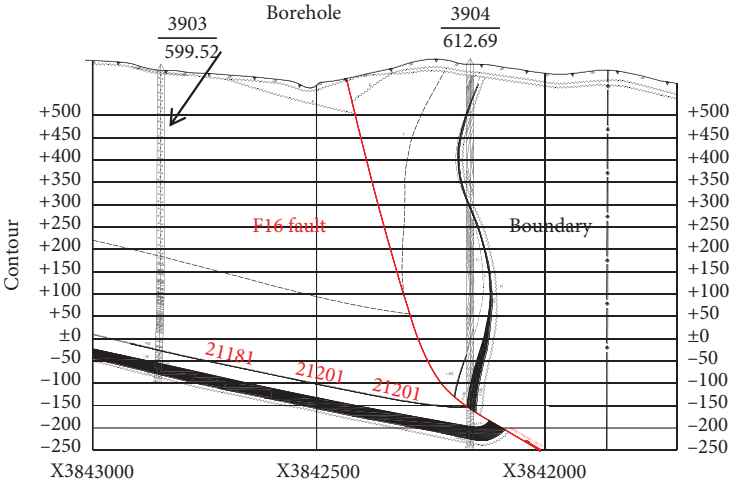

(a) Borehole profile

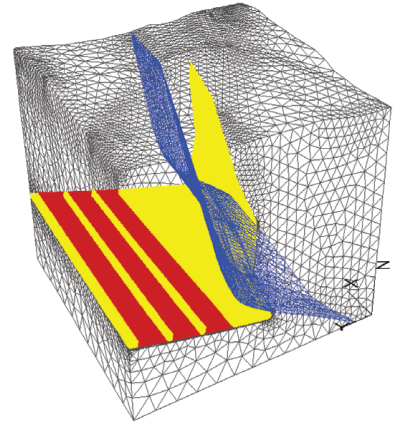

(e) 3D numerical model in FLAC $3 \mathrm{D}$
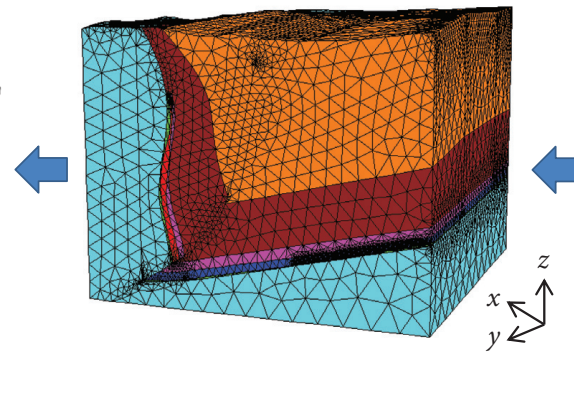

(d) 3D numerical model in ANSYS

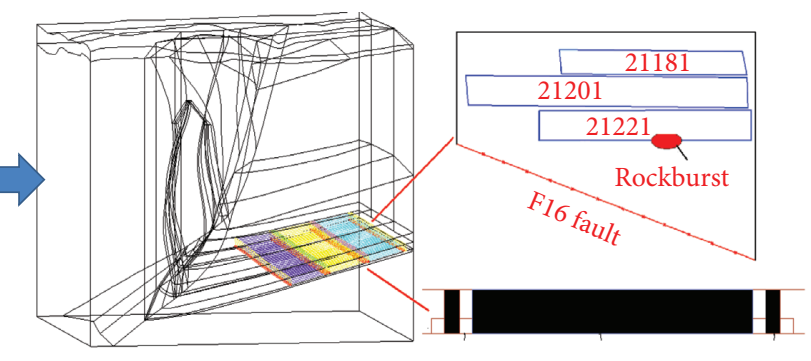

(b) Point line model

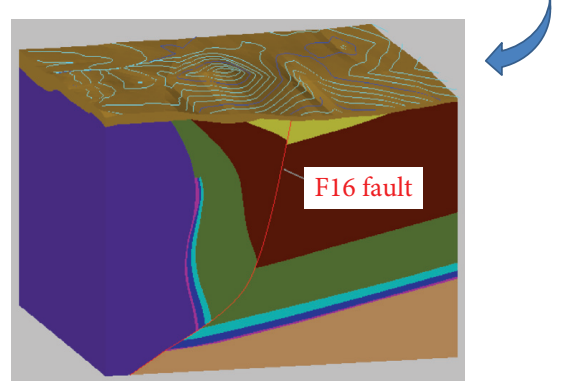

(c) 3D numerical model

Figure 4: The mesh generation of the 3D geological model. 


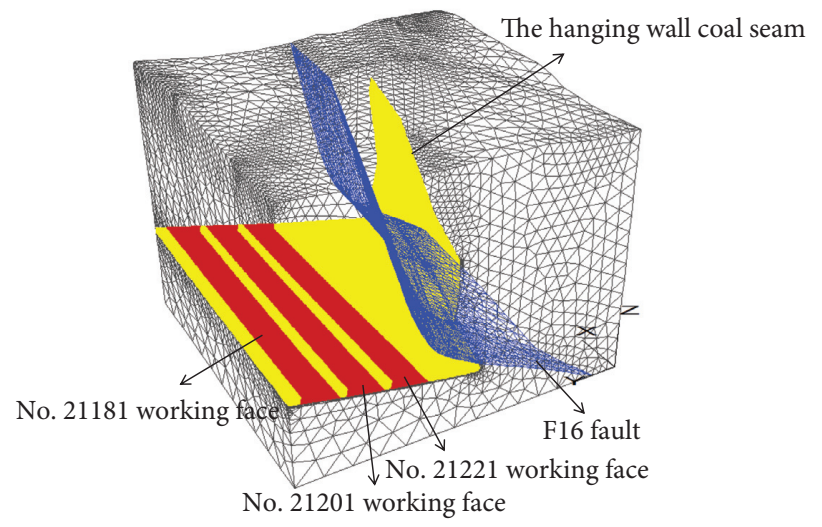

Figure 5: The 3D numerical model.

TABLe 1: In situ stress distribution of Qianqiu mine.

\begin{tabular}{|c|c|c|c|}
\hline Stress measurement & Principal stress & Size value & Direction \\
\hline \multirow{3}{*}{ Point 1} & $\sigma_{z}$ & 18.23 & Vertical \\
\hline & $\sigma_{y}$ & 9.32 & $\mathrm{NE} 31.3^{\circ}$ \\
\hline & $\sigma_{x}$ & 18.01 & NW61.6 \\
\hline \multirow{3}{*}{ Point 2} & $\sigma_{z}$ & 19.54 & Vertical \\
\hline & $\sigma_{y}$ & 11.67 & $\mathrm{NE} 16.6^{\circ}$ \\
\hline & $\sigma_{x}$ & 22.87 & NW75.0 \\
\hline
\end{tabular}

There is a basic assumption of the stress loading method in the paper, namely, $\sigma_{z}{ }^{\prime}=\sigma_{z}=\sigma_{2}$ which indicates that the intermediate principal stress in the original space coordinate system is the same as the intermediate principal stress in the space coordinate system. The basic assumption in this paper coincides to the in situ stress in Qianqiu mine measured by hydraulic fracture. Inversion of in situ stress loading is adopted to improve the accuracy of simulation results. The stress loading method needs to measure the space stress conversion in the north and east direction for the $X$-axis and the $Y$-axis of the coordinate system; namely, the three-dimensional model of the $X$-axis and the $Y$-axis direction is established in this paper. By means of the spatial stress conversion formula in elasticity, the measured spatial in situ stress is converted to the coordinate system where the geological model is located, and the in situ stress in this coordinate system has shear stress:

$$
\begin{aligned}
& \sigma_{y}^{\prime}=\sigma_{x} l_{y^{\prime} x}^{2}+\sigma_{y} l_{y^{\prime} y}^{2}+\sigma_{z} l_{y^{\prime} z}^{2}+2\left(\tau_{x y} l_{y^{\prime} x} l_{y^{\prime}}+\tau_{y z} l_{y y^{\prime}} l_{y, z}+\tau_{z x} l_{y^{\prime} z^{\prime} x} l_{y^{\prime} x}\right) \\
& \sigma_{z}^{\prime}=\sigma_{x} l_{z^{\prime} x}^{2}+\sigma_{y} l_{z^{\prime} y}^{2}+\sigma_{z} l_{z^{\prime} z}^{2}+2\left(\tau_{x y} l_{z^{\prime} x} l_{z^{\prime} y}+\tau_{y z} l_{z^{\prime} y} l_{z^{\prime} z}+\tau_{z x} l_{z^{\prime} z} l_{z^{\prime} x}\right), \\
& \tau_{x y}=\sigma_{x} l_{x^{\prime} x} l_{y^{\prime} x}+\tau_{x y}\left(l_{y^{\prime} x} l_{x^{\prime} y}+l_{x^{\prime} x} l_{y^{\prime} y}\right)+\sigma_{y} l_{x y} l_{y y}+\tau_{y z}\left(l_{y^{\prime} y} l_{x z^{\prime}}+l_{x^{\prime} y} l_{y z^{\prime}}\right)+\sigma_{z} l_{x z} l_{y z}+\tau_{z x}\left(l_{y z^{\prime}} l_{x^{\prime} x}+l_{x z^{\prime}} l_{y^{\prime} x}\right) \text {, } \\
& \tau_{z x}=\sigma_{x} l_{z^{\prime} x} l_{x^{\prime} x}+\tau_{x y}\left(l_{x^{\prime} x} l_{z y^{\prime}}+l_{z^{\prime} x} l_{x y^{\prime}}\right)+\sigma_{y} l_{z^{\prime} y} l_{x^{\prime} y}+\tau_{y z}\left(l_{x y^{\prime}} l_{z^{\prime} z}+l_{z y^{\prime}} l_{x^{\prime} z}\right)+\sigma_{z} l_{z^{\prime} z^{\prime} x^{\prime} z}+\tau_{z x}\left(l_{x^{\prime} z} l_{z^{\prime} x}+l_{z^{\prime} z} l_{x^{\prime} x}\right) \text {, } \\
& \tau_{y^{\prime} z^{\prime}}=\sigma_{x} l_{y^{\prime} x} l_{z^{\prime} x}+\tau_{x y}\left(l_{z^{\prime} x} l_{y^{\prime} y}+l_{y x^{\prime}} l_{z^{\prime} y}\right)+\sigma_{y} l_{y^{\prime} y} l_{z^{\prime} y}+\tau_{y z}\left(l_{z^{\prime} y} l_{y^{\prime} z}+l_{y^{\prime} y} l_{z^{\prime} z}\right)+\sigma_{z} l_{y^{\prime} z} l_{z^{\prime} z}+\tau_{z x}\left(l_{z^{\prime} z^{\prime}} l_{y^{\prime} x}+l_{y^{\prime} z} l_{z^{\prime} x}\right) \text {, } \\
& \tau_{z^{\prime} y^{\prime}}=\tau_{y^{\prime} z^{\prime}} \quad \tau_{z^{\prime} x^{\prime}}=\tau_{x^{\prime} z^{\prime}} \quad \tau_{y^{\prime} x^{\prime}}=\tau_{x^{\prime} y^{\prime \prime}} .
\end{aligned}
$$

3.3. Numerical Calculation Scheme. Due to the complexity of the model, each rock layer is not a horizontal plane, but a curved surface with a certain spatial shape, which also increases the difficulty of fault contact surface. The method of this paper is to merge the hanging wall and footwall strata of the fault, respectively, and then separate the strata after adding interface. In the numerical model, Coulomb failure criterion is used to evaluate shear failure on the contact surface [19]. Mechanical properties of stratus are shown in Table 2. Properties of contact surface are defined as follows: normal stiffness is $2 \mathrm{GPa} / \mathrm{m}$, shear stiffness is $5 \mathrm{GPa} / \mathrm{m}$, internal friction angle is 20 degrees, and cohesion is $0.5 \mathrm{MPa}$.

The mining sequence of the working face is, firstly, mining 21181 working face, then mining 21201 working face, and, finally, mining 21221 working face. Simulation of excavation step distance is set to $40 \mathrm{~m}$. The mining process 
TABLE 2: Mechanical properties of stratus.

\begin{tabular}{lcccccc}
\hline Rock stratum & $\begin{array}{c}\rho \\
\left(\mathrm{kg} / \mathrm{m}^{3}\right)\end{array}$ & $\begin{array}{c}E \\
(\mathrm{GPa})\end{array}$ & $\mu$ & $\begin{array}{c}\mathrm{C} \\
(\mathrm{MPa})\end{array}$ & $\begin{array}{c}\Phi \\
\left({ }^{\circ}\right)\end{array}$ & $\begin{array}{c}\sigma_{\mathrm{t}} \\
(\mathrm{MPa})\end{array}$ \\
\hline $\begin{array}{l}\text { Overlying } \\
\text { strata }\end{array}$ & 2700 & 17.60 & 0.23 & 6.0 & 33 & 2.0 \\
Hard strata & 2707 & 25.64 & 0.22 & 7.0 & 33 & 4.0 \\
Main roof & 2807 & 27.93 & 0.21 & 5.0 & 35 & 3.5 \\
$\begin{array}{l}\text { Immediate } \\
\text { roof }\end{array}$ & 2173 & 5.14 & 0.24 & 2.0 & 32 & 1.0 \\
2 $^{\#}$ coal seam & 1440 & 3.30 & 0.16 & 1.5 & 35 & 0.9 \\
Direct bottom & 2673 & 22.65 & 0.25 & 5.0 & 30 & 3.0 \\
Basic bottom & 2461 & 24.62 & 0.35 & 6.5 & 35 & 3.5 \\
\hline
\end{tabular}

accompanies the filling process to simulate the caving of the immediate roof, the basic roof, and goaf compaction. The mining sequence of the model is shown in Table 3.

In the numerical model, monitoring lines are both arranged along the coal seam strike and inclination to monitor the stress distribution characteristics of original rock before mining and the dynamic variation of mininginduced stress in the process of mining.

\section{Numerical Simulation Results Analysis}

4.1. Original Stress Distribution. In the simulation, original stress equilibrium is reached, and then the working face is mined. The maximum and minimum principal stress distribution of the model is shown in Figure 6.

The principal stress of each stratum is compressive stress, and the stress level is gradually increased from the upper to the lower of the model. The fault has a certain influence on the original stress distribution. The stress value changes and breaks on the fault surface and return to normal value far away from the fault.

Figure 7 shows the original rock stress distribution of coal seam. It can be seen that the stress distribution of coal seam is uneven, and the closer to the fault along the coal seam dip direction, the greater the stress value. In order to analyze the stress distribution, the stress value is extracted along the monitoring line of coal seam inclination and drawn into a curve, as shown in Figure 8.

It can be seen from the original rock stress curve that the coal seam stress distribution is discontinuous under the influence of coal seam dip angle and fault. The vertical stress is $18-22 \mathrm{MPa}$, the maximum horizontal stress is $20-28 \mathrm{MPa}$, and the minimum horizontal stress is $12-16 \mathrm{MPa}$. The stress value near the fault is higher in the deep coal seam. The horizontal stress of coal seam is higher than the vertical stress. The distribution of stress field represents the regulation that $\sigma_{H}>\sigma_{V}>\sigma_{h}$. The stress field in the mining area is mainly the tectonic stress field and the results of the inversion stress are similar to in situ stress measured in field. The following calculation and analysis are based on the results above.

4.2. Mining-Induced Stress Evolution. The vertical stress distribution of coal seam in the process of mining is shown in Figure 9. The vertical stress of 21181 working face, 21201
TABle 3: Mining sequence of the model.

\begin{tabular}{lccc}
\hline Mining sequence & Advancing distance & Step & Total step \\
\hline $\mathrm{x} 0$ & Balance calculation & 6766 & 6766 \\
$\mathrm{x} 1$ & $21181-40 \mathrm{~m}$ & 500 & 7266 \\
$\mathrm{x} 2$ & $21181-80 \mathrm{~m}$ & 500 & 7766 \\
- & - & 500 & - \\
$\mathrm{x} 15$ & $21181-600 \mathrm{~m}$ & 500 & 14266 \\
$\mathrm{y} 1$ & $21201-40 \mathrm{~m}$ & 500 & 14766 \\
$\mathrm{y} 2$ & $21201-80 \mathrm{~m}$ & 500 & 15266 \\
- & - & 500 & - \\
$\mathrm{y} 23$ & $21201-920 \mathrm{~m}$ & 500 & 25766 \\
$\mathrm{z} 1$ & $21221-40 \mathrm{~m}$ & 500 & 26266 \\
$\mathrm{z} 2$ & $21221-80 \mathrm{~m}$ & 500 & 26766 \\
- & - & 500 & - \\
$\mathrm{z} 22$ & $21221-880 \mathrm{~m}$ & 500 & 36766 \\
\hline
\end{tabular}

working face, and 21221 working face is only listed in the limited space when the face is mined to different positions.

Stress concentration is formed in the front and side of the coal wall in the process of advancing the working face, and the goaf is the stress reduction area. The results are consistent with the stress shell theory [20]. The magnitude of the mining-induced stress, which is formed when the mining face is extracted, gradually increased during the mining process. The measuring point records the change of abutment stress in the process of advancing the working face and matches abutment pressure curves of each working face in the mining process, as illustrated in Figure 10.

It can be seen that the initial vertical stress of 21181 working face is $18.2 \mathrm{MPa}$, and the peak stress reaches 24.2 MPa after being affected by mining. The stress increase is $32.9 \%$, and the stress concentration coefficient is 1.32 . When mining 21201 working face, the original rock stress rises to $23.1 \mathrm{MPa}$, the peak stress is $32.3 \mathrm{MPa}$, the stress increase is $39.8 \%$, and the stress concentration coefficient is 1.39. Further approaching fault mining, when mining 21221 working face, the original rock stress rises to $28.7 \mathrm{MPa}$, the peak stress is $39.2 \mathrm{MPa}$ under the influence of mining, the stress increase is $36.6 \%$, and the stress concentration coefficient is 1.36 . When the original rock stress was before the work of 21221, the stress of coal body has exceeded the uniaxial compressive strength of coal seam. It has been tested in laboratory that the strength of No. 2 coal seam in Qianqiu mine is between 15 and $25 \mathrm{MPa}$, and the average strength is $22.47 \mathrm{MPa}$, which is close to the stress condition of rock burst. Under the dynamic disturbance, rock burst is easy to occur.

The horizontal stress and vertical stress change rules of coal seam during mining were recorded along the coal seam dip line, as shown in Figure 11.

It can be seen that the peak value of horizontal stress in the dipping direction of 21181 working face is $22.5 \mathrm{MPa}$ and the peak value of vertical stress is $27.8 \mathrm{MPa}$. When mining 21201 working face, the peak value of horizontal stress in the inclined direction of working face is $33.4 \mathrm{MPa}$, the peak value of vertical stress is $38.9 \mathrm{MPa}$, the increase rate of horizontal stress is $48.4 \%$, and the increase rate of vertical stress is $39.9 \%$. The peak value of horizontal stress is 23.5 $\mathrm{MPa}$ and the peak value of vertical stress is $32.2 \mathrm{MPa}$ at 


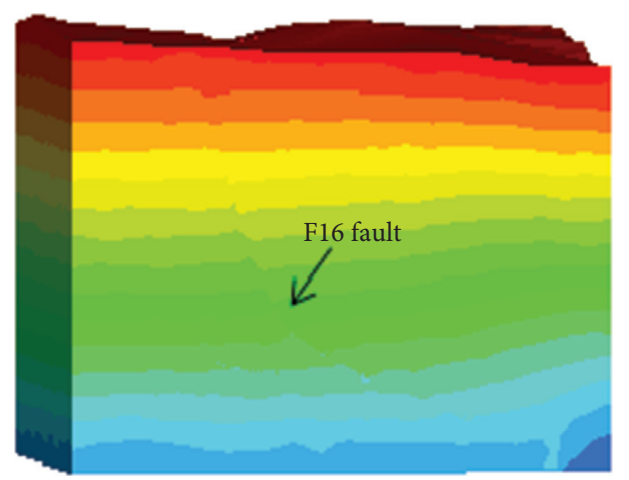

(a)

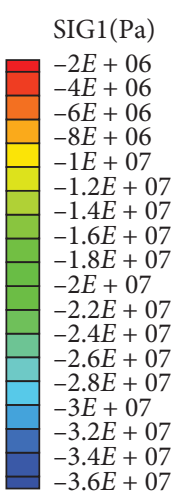

$-3.6 E+07$

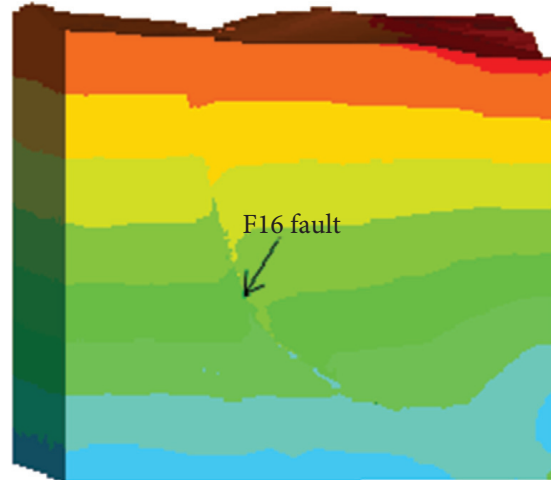

(b)

Figure 6: Distribution of principal stress. (a) Maximum principal stress. (b) Minimum principal stress.

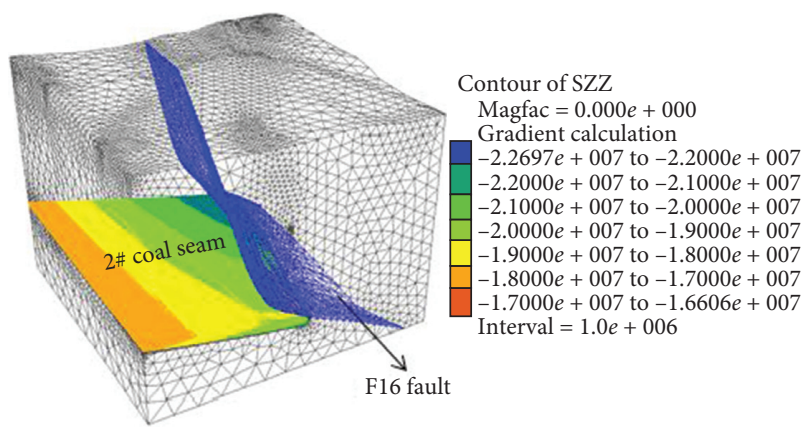

(a)

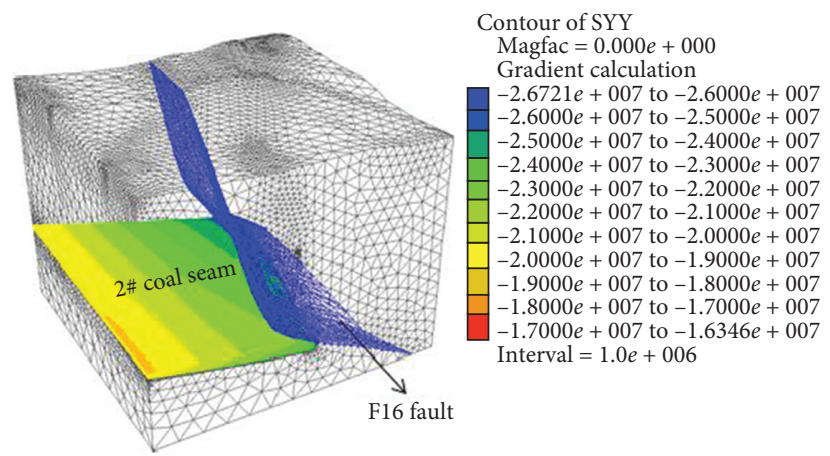

(b)

Figure 7: Vertical and horizontal stress distribution of coal seam.

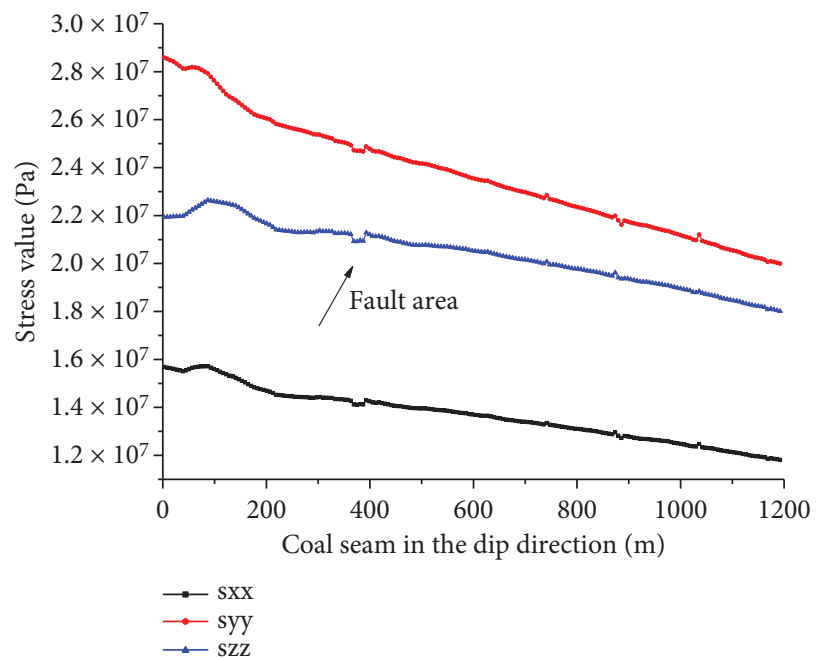

Figure 8: Distribution of stress in coal seam.

21221 working face. Compared with 21201 working face, both horizontal stress and vertical stress are decreased. It shows that there is a critical distance when mining in fault area. When the distance is less than the critical distance, the stress of coal seam increases. When the critical distance is greater than the adjacent distance, the stress of coal seam decreases. When analyzing the influence of fault on working face, the influence distance of fault is usually determined according to the plane position of intersection of fault plane and working face. Because of the different fault occurrence, 


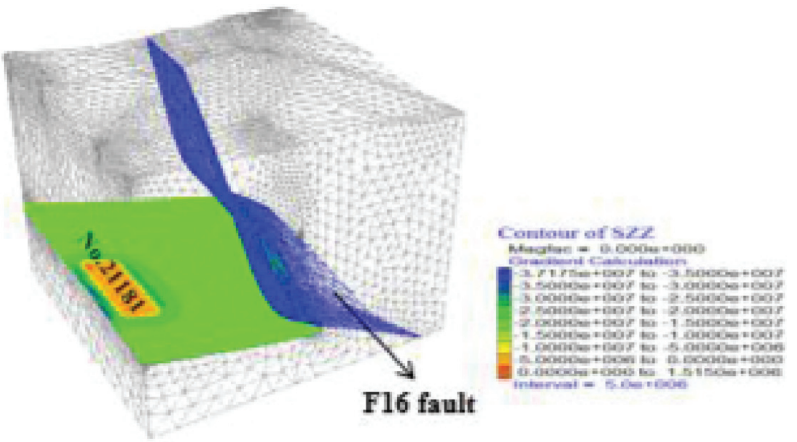

(a)

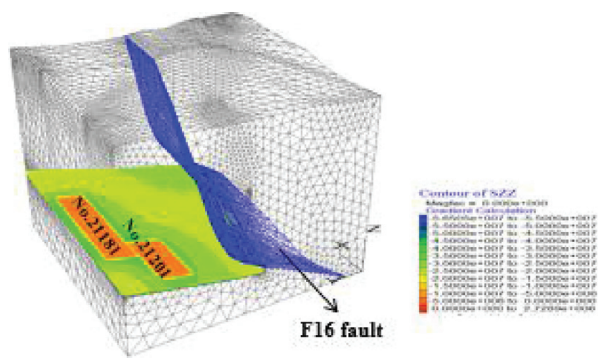

(b)

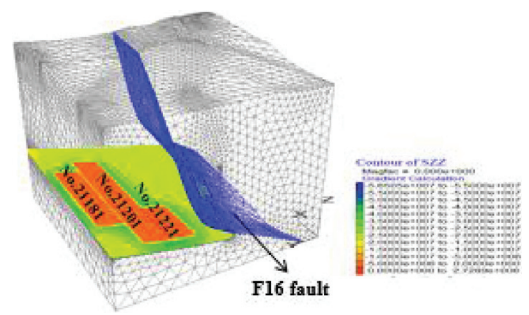

(c)

Figure 9: The evolution process of vertical stress in coal seam. (a) Mining 21181 working faces. (b) Mining 21201 working face. (c) Mining 21221 working face.

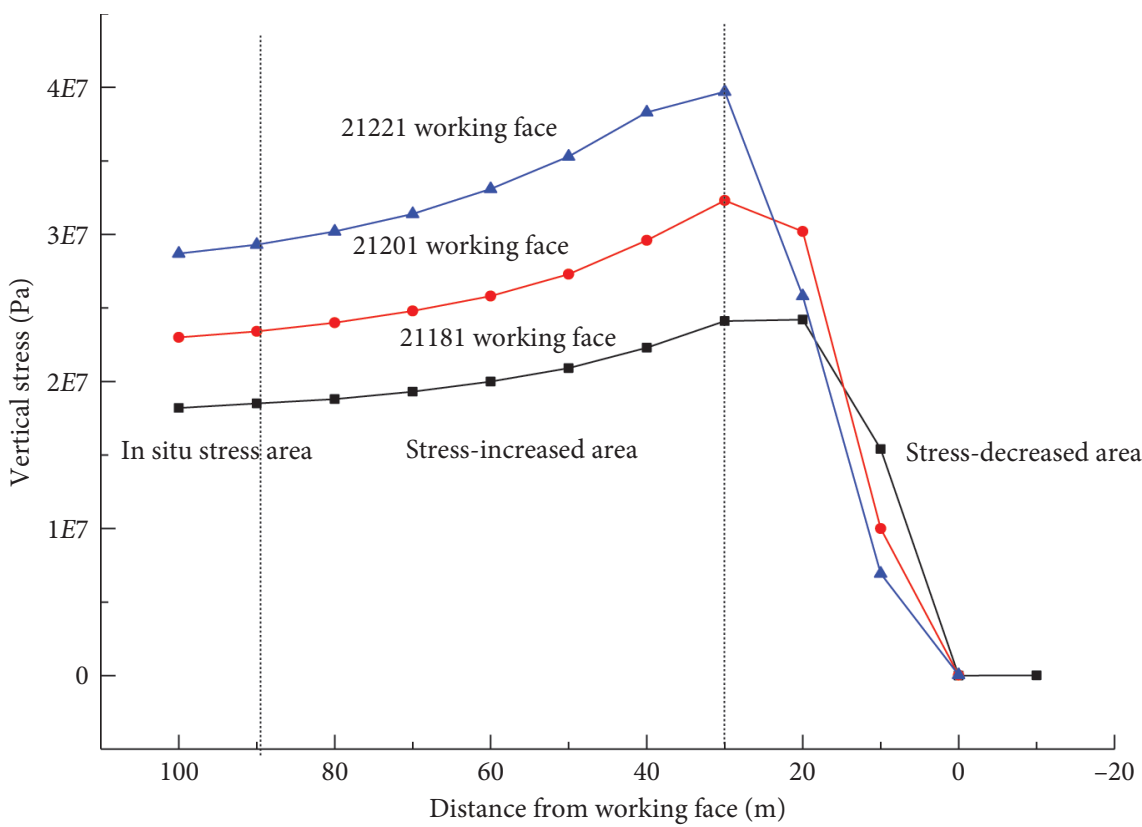

FIGURE 10: Comparison of abutment pressure curves of each working face.

the fault cutting the upper strata of the working face has affected the roof of the working face. When evaluating the influence of the fault on the working face, it should be comprehensively considered the fault occurrence. The influence distance of low angle fault is far, while the influence distance of high angle fault is short.

Figure 12 presents the principal stress and displacement vector when mining 21201 working face. The footwall of F16 fault is a high stress concentration area. The rock mass in the footwall of the fault twists to the goaf with the lateral coal seam of 21201 working face as the support. Affected by F16 fault and the huge thick gravel rock in the roof, the coal seam near the fault accumulates a large amount of elastic strain energy. It can be judged that the coal seam in 21201 working face is in the stress limit state and the risk of rock burst is high. 


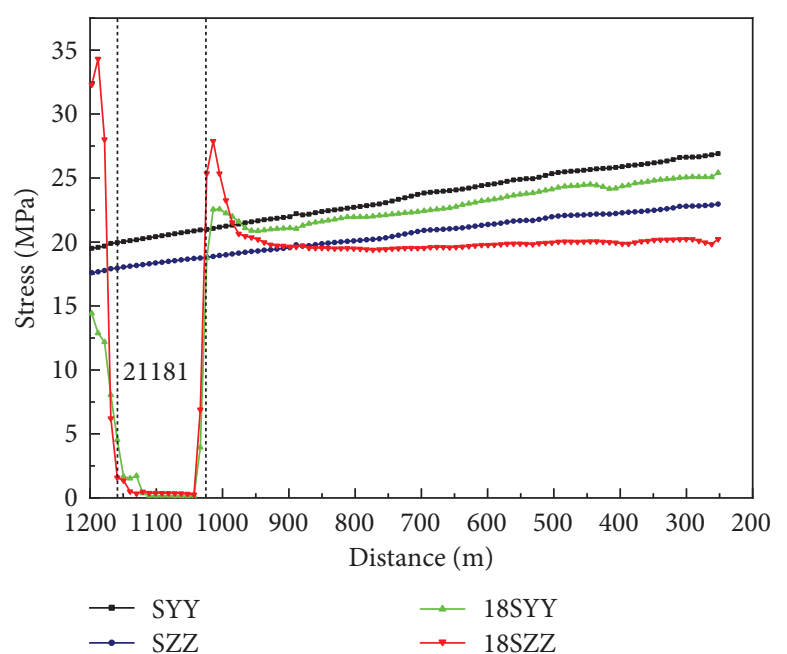

(a)

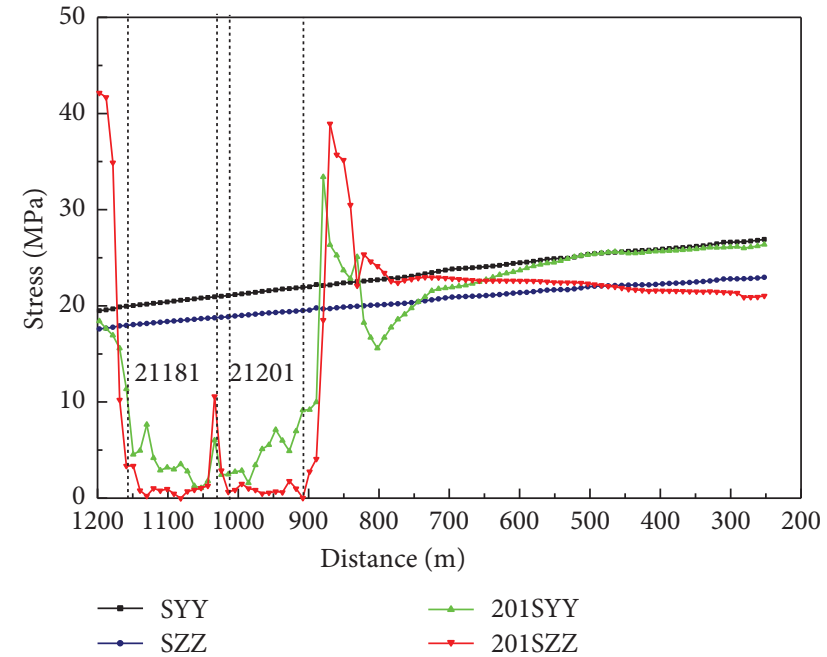

(b)

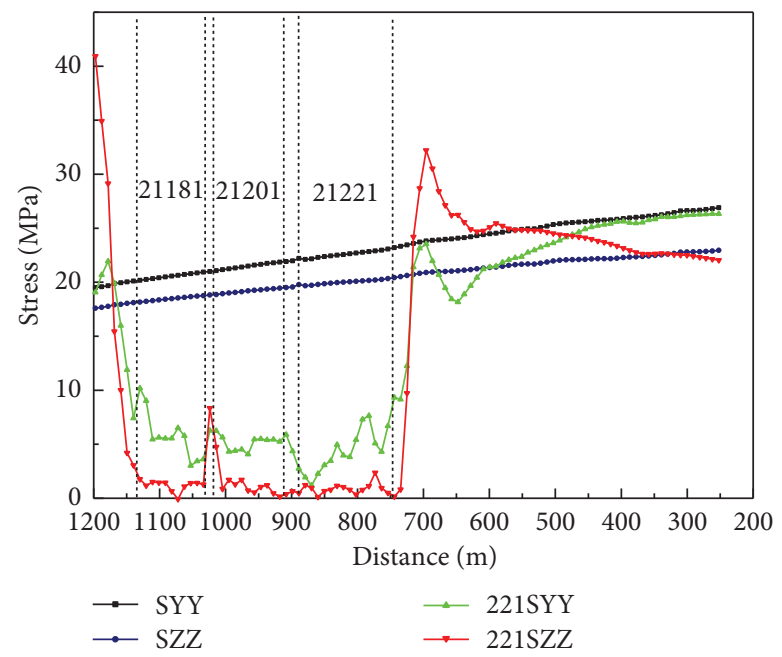

(c)

Figure 11: The stress distribution curve along the coal seam during mining. (a) Mining No. 21181 working face. (b) Mining No. 21201 working face. (c) Mining No. 21221 working face.

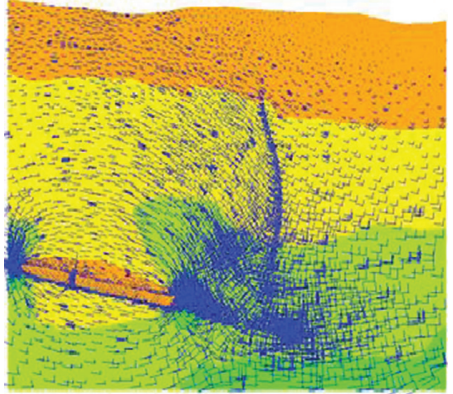

(a)

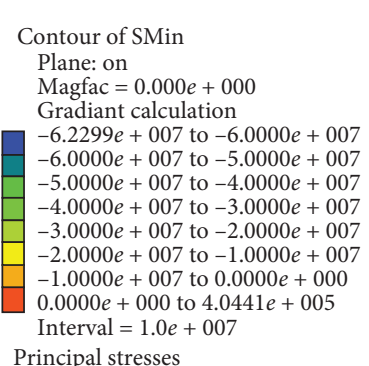

Principal stresses

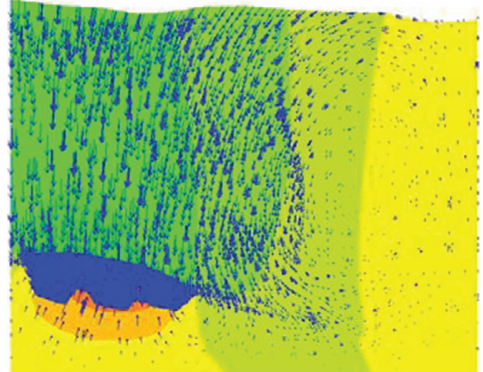

Contour of $Z$-displacement Plane: on Magfac $=0.000 e+000$

$-1.2251 e+000$ to $-1.2000 e+000$ $-1.2000 e+000$ to $-1.0000 e+000$ $-1.0000 e+000$ to $-8.0000 e-001$ $-8.0000 e-001$ to $-6.0000 e-001$ $-6.0000 e-001$ to $-4.0000 e-001$ $-6.0000 e-001$ to $-4.0000 e-001$ $-4.0000 e-001$ to $-2.0000 e-001$
$-2.0000 e-001$ to $0.0000 e+000$ $-2.0000 e-001$ to $0.0000 e+000$
$0.0000 e+000$ to $2.0000 e-001$ $2.0000 e-001$ to $4.0000 e-001$ $4.0000 e-001$ to $6.0000 e-001$ $6.0000 e-001$ to $6.3214 e-001$ Interval $=1.0 e-001$

(b)

FIgURE 12: Principal stress and displacement vector. (a) Maximum principal stress vector. (b) Displacement vector.

4.3. Fault Slip Behavior under Mining. Make a profile along the coal seam inclination, and the variation shear stress in surrounding rock during the mining process of the working face is shown in Figure 13.
It can be seen from that during the process of mining near the fault, the change of fault stress at the roof position is mainly caused by the increase of shear stress. When mining the 21181 working face, the shear stress on both hanging wall 


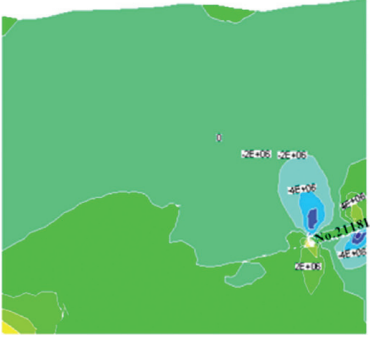

(a)

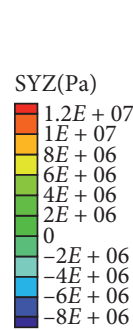

$-8 E+06$

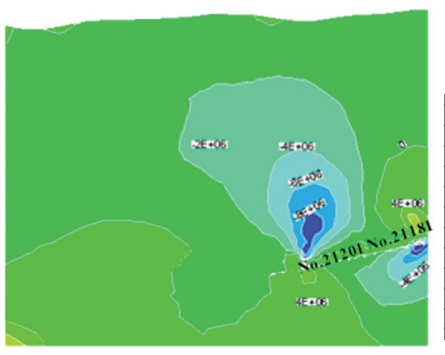

(b)

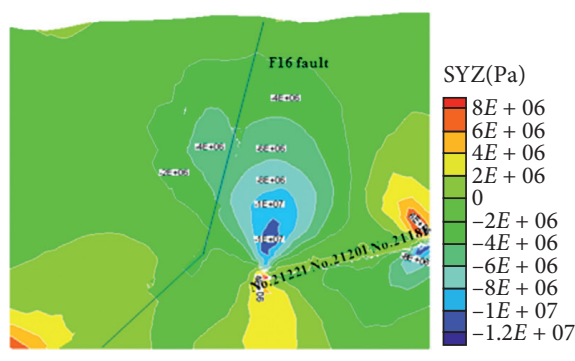

(c)

Figure 13: Distribution of shear stress during mining process. (a) Mining 21181 working face. (b) Mining 21201 working face. (c) Mining 21221 working face.

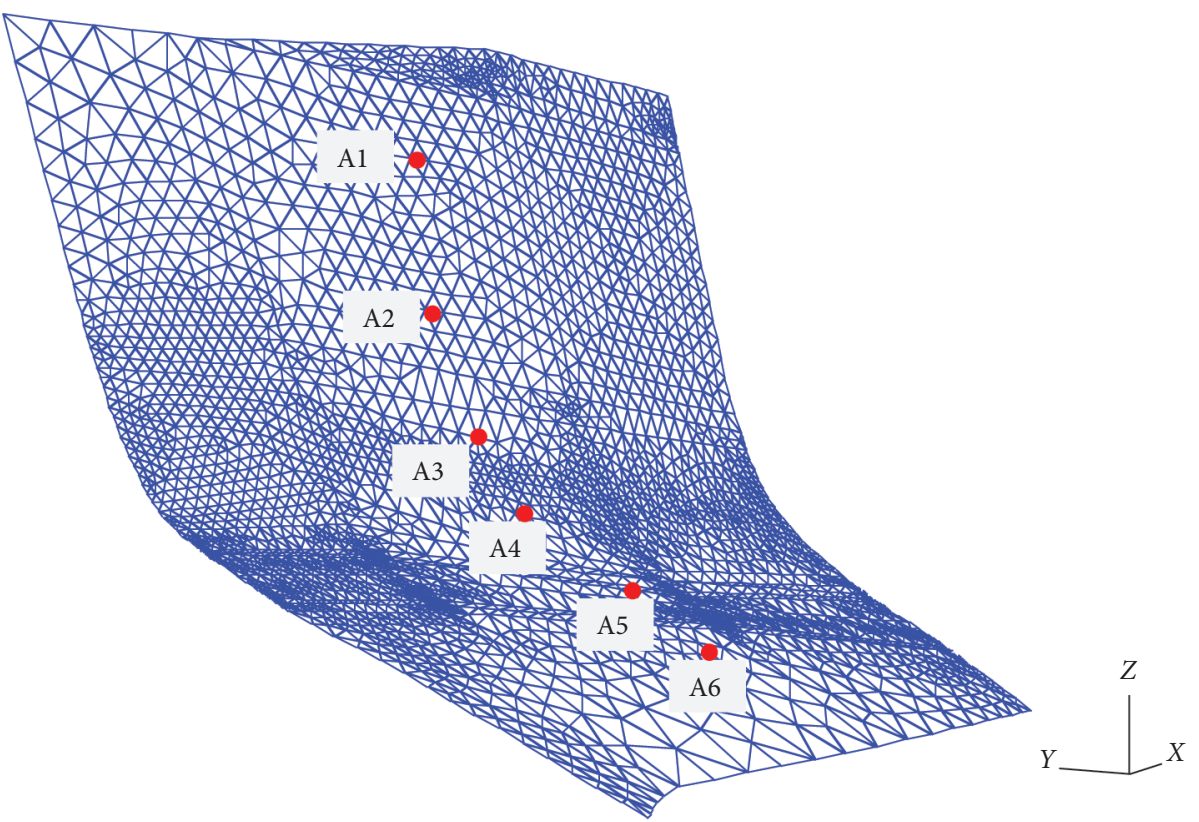

- A1-A6 monitoring points

(a)

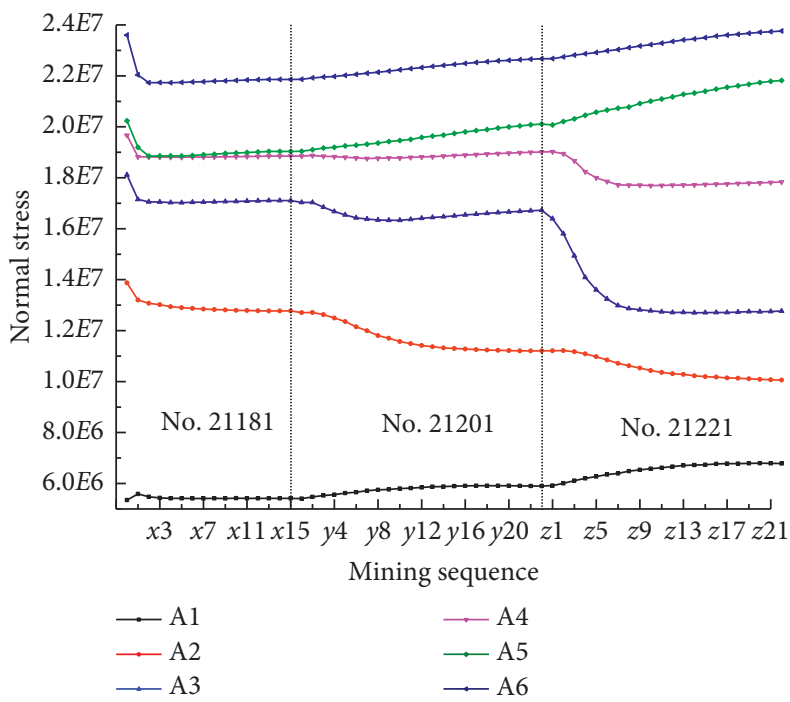

(b)

FIgURE 14: Continued. 


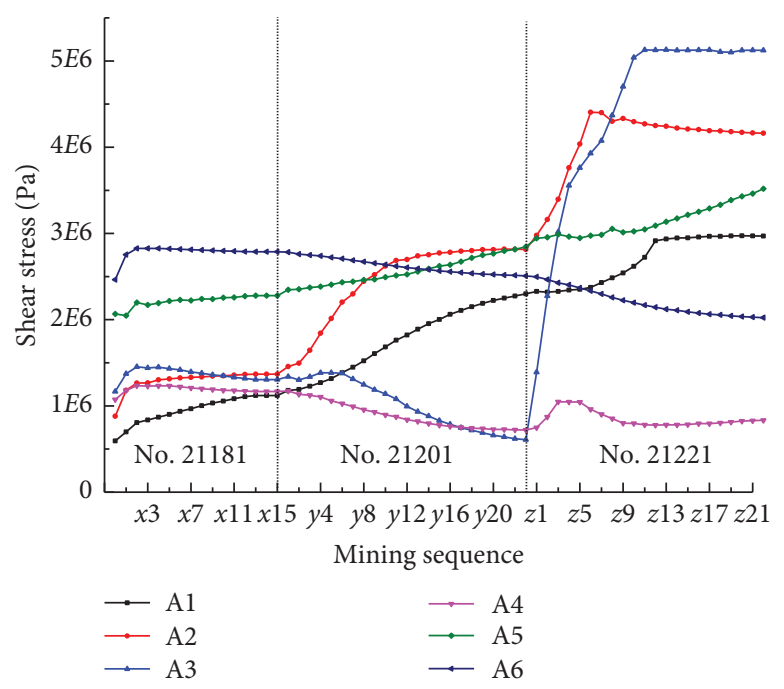

(c)

FIGURE 14: Stress variation on the fault plane. (a) Monitoring points on fault surface. (b) Change of normal stress. (c) Change of shear stress.
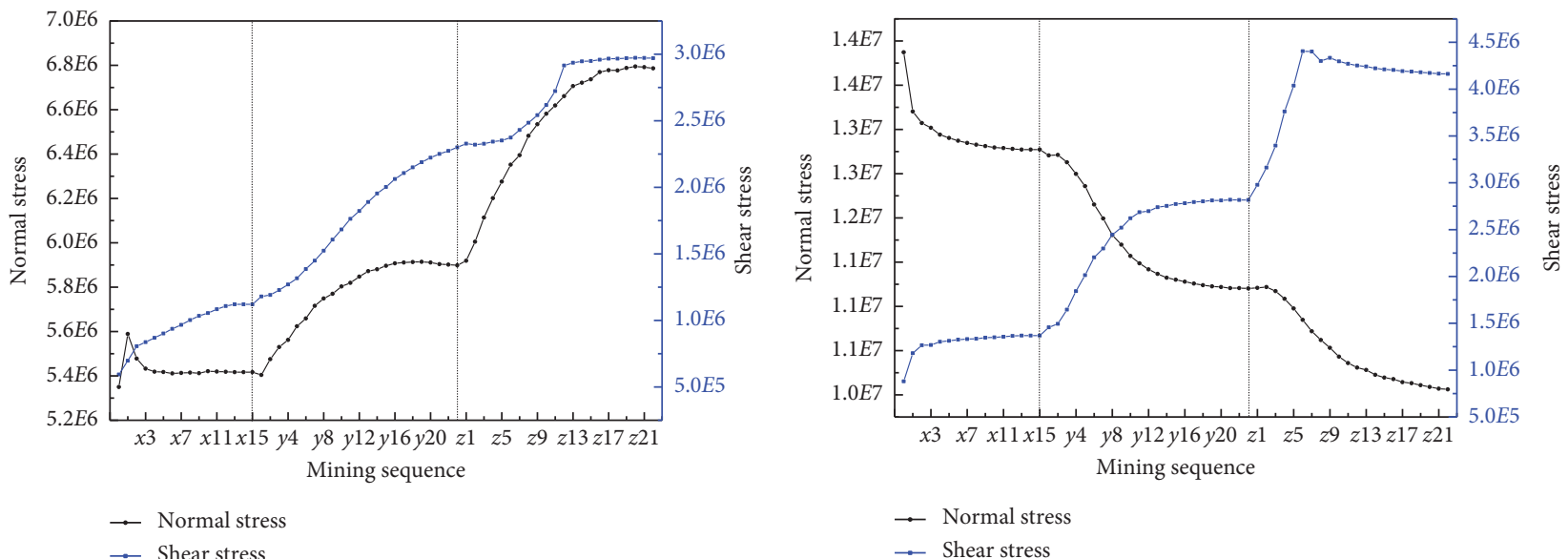

(a)

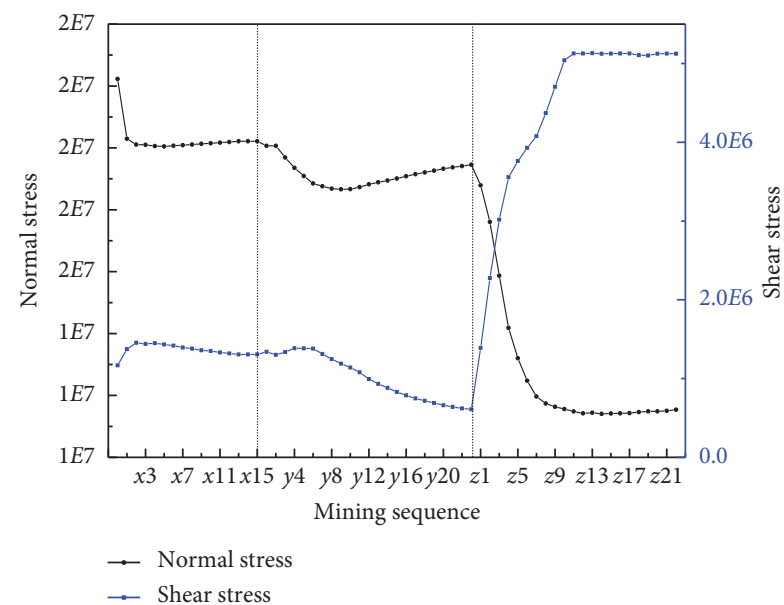

(b)

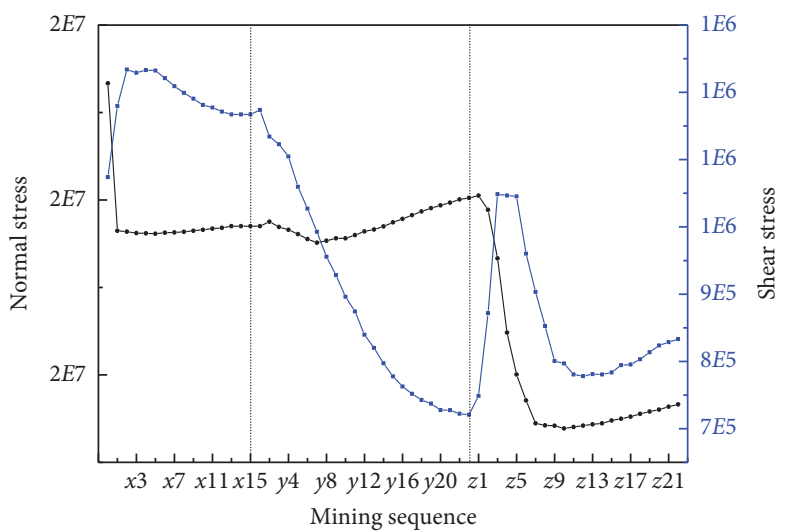

- Shear stress

$\rightarrow$ Normal stress

- Shear stress

(c)

(d)

Figure 15: Continued. 


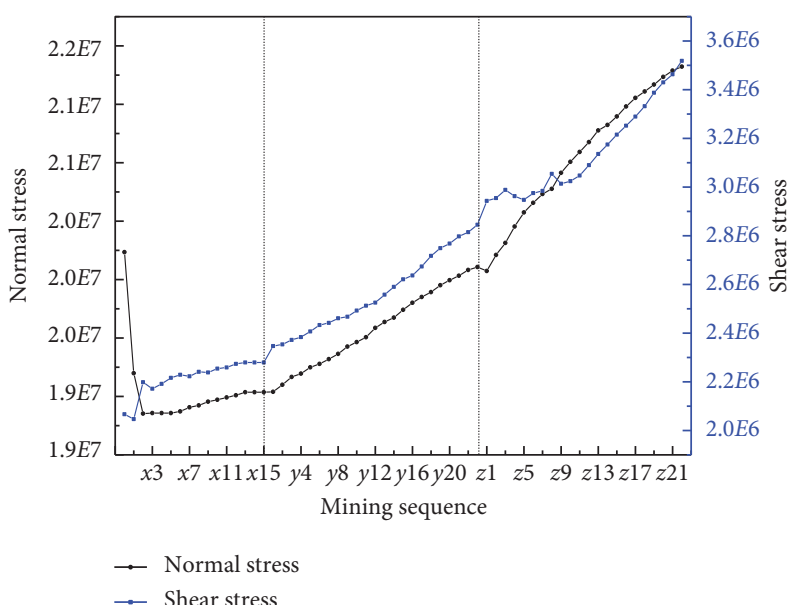

(e)

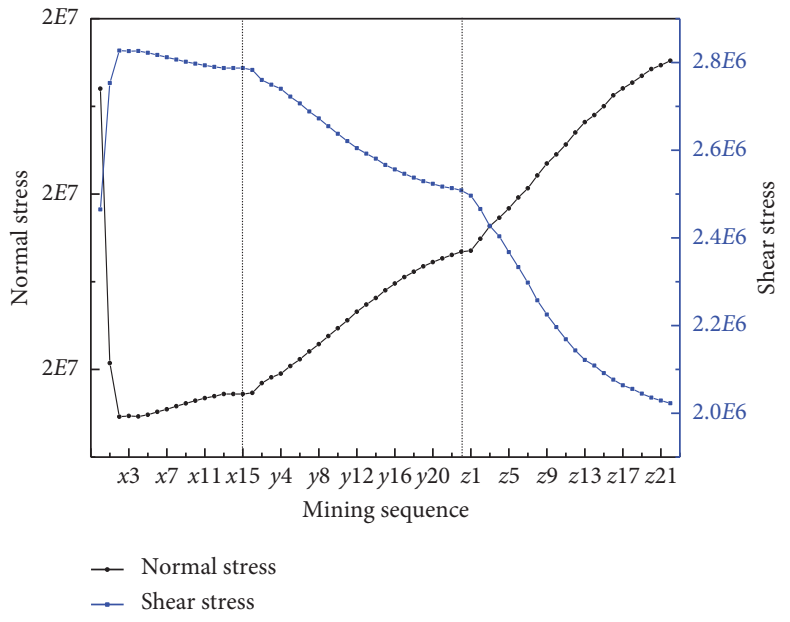

(f)

FIgURE 15: Stress variation of monitoring points. (a) A1 point. (b) A2 point. (c) A3 point. (d) A4 point. (e) A5 point. (f) A6 point.

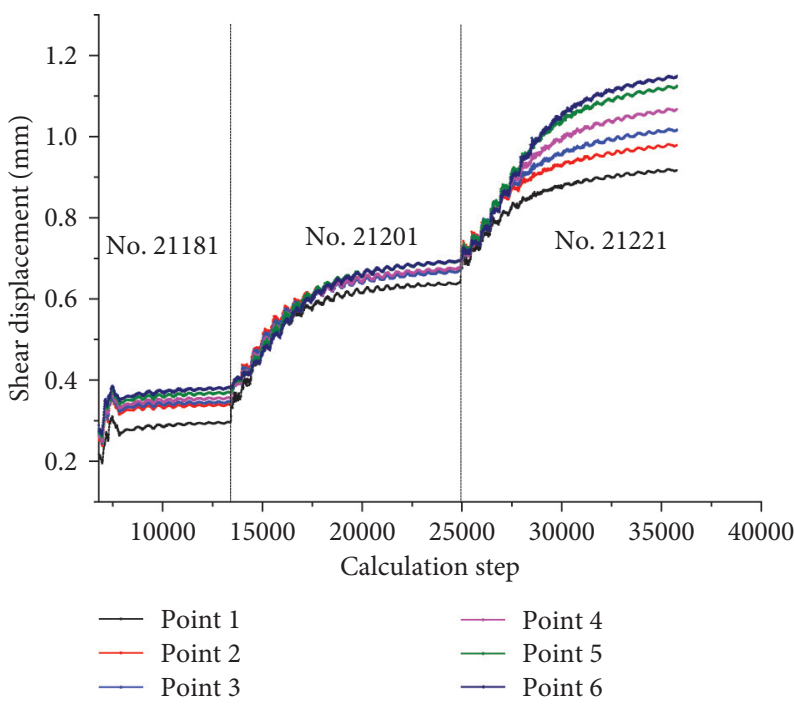

FIGURE 16: Shear displacement of monitoring points.

and footwall of the F16 fault is the same, and mining does not affect the F16 fault at this stage. When mining the 21201 working face, the shear stress difference appears on both sides of the F16 fault. When mining the 21221 working face, the shear stress difference between the footwall and hanging wall of F16 fault continues to increase. The existence of fault makes the original high stress area is divided, and the fault plays a controlling role in the process of stress change and migration.

Monitoring points are arranged on the fault to obtain the spatial and temporal distribution of normal stress and shear stress in different layer during the process of the mining. Mining sequence of working faces is shown in Table $3, x 0$ is the original stress equilibrium process, $x 1-x 15$ is the mining 21181 working face, $y 1-y 23$ is mining 21201 working face, and $z 1-z 22$ is mining 21221 working face. During the mining process, the normal stress and shear stress variation of the monitoring points are shown in Figure 14.

The initial state of normal and shear stress of each measuring point increases from the overburden to the floor which conforms to the distribution law of in situ stress. The normal stress is greater than the shear stress. The change time of each layer on fault is different under mining; stress variation of monitoring points is shown in Figure 15. Slip mechanism of the fault can be divided into two types. One type is the normal stress which is continuously reduced, and the shear stress increases rapidly. This situation mainly occurs in rock strata at higher position, such as A2-A4 points. Another type is both normal stress and shear stress increase, but the increase range of shear stress is larger than that of normal stress. This situation mainly occurs in coal seam area, such as A5 point. The stress difference on the fault 
plane is related to the stress evolution distribution of surrounding rock after coal mining. The farther away from the coal seam, the earlier the stress change starts. The change of shear stress is mainly increased, while the change of normal stress is mainly decreased, and the change of shear stress is earlier and greater than that of normal stress; the response of shear stress to mining is more sensitive [21-24].

The closer the distance from the mining seam is, the higher the normal stress and shear stress are. The reason is that the movement and evolution of overburden caused by mining disturbance is highly related [25-29]. The shear displacement of each point is shown in Figure 16.

With working face close to fault, fault shear displacement is growing rapidly. The closer the fault is to the coal seam, the greater the slip is. The farther away from each other, the more the damage and the slip of rock strata gradually weaken. The fault slip increases continuously, and the risk of fault slip and instability is greater. Therefore, it can be concluded that the risk of rock burst induced by fault reactivation is the greatest when mining 21221 working face.

\section{Conclusion}

Based on the geological mining conditions of Qianqiu mine as engineering background, the refined numerical simulation research was carried out to analyze the surrounding rock stress evolution in the mining process near F16 fault. The following conclusions were drawn.

(1) According to the geological borehole and F16 fault profile information of Qianqiu mine, a three-dimensional refined numerical model reflecting the actual stratigraphic conditions of No. 21 mining area in Qianqiu mine was constructed.

(2) Based on the in situ stress data of No. 21 mining area, the stress is applied to the coordinate system of the numerical model through the spatial stress transformation formula. Numerical simulation of the initial balance calculation of the working face is before mining. The vertical stress is $18-22 \mathrm{MPa}$, the maximum horizontal stress is $20-28 \mathrm{MPa}$, and the minimum horizontal stress is $12-16 \mathrm{MPa}$. The distribution of stress field represents a regulation that $\sigma_{H}>\sigma_{V}>\sigma_{h}$. The stress field in the mining area is mainly the tectonic stress field, and the results of the inversion stress are similar to in situ stress measured in field, which verifies the rationality of the stress loading mode.

(3) It shows that there is a critical distance when mining near fault area. When evaluating the influence of the fault on the working face, it should be comprehensively considered the fault occurrence. Under the influence of fault dip angle and mining, the stress state of each measuring point on the F16 fault plane is different, and the normal stress on the upper fault plane tends to decrease, while the shear stress on the upper fault plane tends to increase. The closer the working face is to the fault, the more obvious the disturbance effect of mining on the fault is. The footwall of F16 fault is a high stress concentration area. Affected by F16 fault and the huge thick gravel rock in the roof, the coal seam near the fault accumulates a large amount of elastic strain energy, which increases the potential of rock burst hazards in the process of mining.

\section{Data Availability}

The data used for conducting classifications are available from the corresponding author upon request.

\section{Conflicts of Interest}

The authors declare that there are no conflicts of interest regarding the publication of this paper.

\section{Acknowledgments}

This research was funded by the Natural Science Foundation of Anhui Province (1908085QE184) and Independent Research Project of State Key Laboratory of Mining Response and Disaster Prevention and Control in Deep Coal Mines (SKLMRDPC19ZZ04).

\section{References}

[1] Y. Jiang and Y. Zhao, "State of the art: investigation on mechanism, forecast and control of coal bumps in China," Chinese Journal of Rock Mechanics and Engineering, vol. 34, no. 11, pp. 2188-2204, 2015.

[2] X. Hao, W. Du, Y. Zhao et al., "Dynamic tensile behaviour and crack propagation of coal under coupled static-dynamic loading," International Journal of Mining Science and Technology, vol. 30, no. 5, pp. 659-668, 2020.

[3] Q. Qi, Y. Li, S. K Zhao et al., "Discussion on the mechanism and control of coal bump among mine group," Journal of China Coal Society, vol. 44, no. 1, pp. 141-150, 2019.

[4] J. Lou, F. Gao, J. Yang et al., "Characteristics of evolution of mining-induced stress field in the longwall panel:insights from physical modeling," in International Journal of Coal Science and TechnologySpringer, Berlin, Germany, 2021.

[5] A. Keneti and B. A. Sainsbury, "Review of published rockburst events and their contributing factors," Engineering Geology, vol. 246, pp. 361-373, 2018.

[6] W. Cai, L. Dou, G. Wang et al., "Mechanism of fault reactivation and its induced coal burst caused by coal mining activities," Journal of Mining \& Safety Engineering, vol. 36, no. 6, pp. 1193-1202, 2019.

[7] A. Sainoki and H. S. Mitri, "Back analysis of fault-slip in burst prone environment," Journal of Applied Geophysics, vol. 134, pp. 159-171, 2016.

[8] F. X. Jiang, Q. D. Wei, C. W. Wang et al., “Analysis of rock burst mechanism in extra-thickcoal seam controlled by huge thick conglomerate and thrust fault," Journal of China Coal Society, vol. 7, pp. 1191-1196, 2014.

[9] Y. An, C. B. Wang, L. M. Dou et al., "Dynamic manifestation mechanism of mining on the island coalface along fault and dynamic pre-warning of seismic waves with seismic tomography," Journal of Mining \& Safety Engineering, vol. 34, no. 3, pp. 411-417, 2017.

[10] H. Xianjie, W. Yingnan, Y. Ke et al., "Anisotropy of crack initiation strength and damage strength of coal reservoirs," 
Petroleum Exploration and Development, vol. 48, no. 1, pp. 243-255, 2021.

[11] X. Shen, S. Li, D. Li et al., "Geological laws of rock burst occurrence in Yima Coal-field," Journal of China Coal Society, vol. 40, no. 9, pp. 2015-2020, 2015.

[12] M. Li, D. Zhongh, Z. Qin, and J. Liu, "Refined modeling for numerical simulation of engineering rock mass structures based on 3D geological model," Chinese Journal of Rock Mechanics and Engineering, vol. 26, no. 9, pp. 1893-1898, 2007.

[13] Y. Xia, W. B. Shi, and C. S. Ni, "Study oncoupling of 3D visualization with numerical simulation for powerhouse excavation of a certain hydro-junction," Rock and Soil Mechanics, vol. 26, no. 6, pp. 968-972, 2005.

[14] W. Cai, L. Dou, Z. Li et al., "Microseismic multidimensional information identification and spatio-temporal forecasting of rock burst:A case study of Yima Yuejin coal mine, Henan, China," Chinese Journal of Geophysics, vol. 57, no. 8, pp. 2688-2700, 2014.

[15] H. Wang, R. Shi, D. Deng, Y. Jiang, G. Wang, and W. Gong, "Characteristic of stress evolution on fault surface and coal bursts mechanism during the extraction of longwall face in Yima mining area, China," Journal of Structural Geology, vol. 136, Article ID 104071, 2020.

[16] Z. H. Jiao, Y. X. Zhao, Y. D. Jiang, H. Wang, Z. G. Lu, and X. Z. Wang, "Fault damage induced by mining and its sensitivity analysis of influencing factors," Journal of China Coal. Society, vol. 42, no. Suppl. 1, pp. 36-42, 2017.

[17] J. Liu, T. Wang, W. Ding et al., "Induction mechanisms of coal bumps caused by thrust faults during deep mining," Journal of China Coal Society, vol. 43, no. 2, pp. 405-416, 2018.

[18] Y. Wu, J. He, L. Si et al., "Study on geostress distribution law of deep mine in Yima Mining Area," Coal Science and Technology, vol. 46, no. 10, pp. 16-21, 2018.

[19] C. G. I. Itasca, FLAC3D, (Fast Lagrangian Analysis of Continua in 3 Dimensions), Itasca Consulting Group, Minneapolis, MN, USA, 2006.

[20] G. Xie, "Mechanical characteristics of fully mechanized topcoal caving face and surrounding rock stress shell," Journal of China Coal Society, vol. 30, no. 3, pp. 309-313, 2005.

[21] P. Kong, L. S. Jiang, J. M. Shu, and L. Wang, "Mining stress distribution and fault-slipbehavior: a case study of fault influenced longwall coal mining," Energies, vol. 12, no. 13, pp. 1-21, 2019.

[22] H. G. Ji, H. S. Ma, J. A. Wang, Y. H. Zhang, and H. Cao, "Mining disturbance effect and mining arrangements analysis of near-fault mining in high tectonic stress region," Safety Science, vol. 50, no. 4, pp. 649-654, 2012.

[23] M. Cai, "Prediction and prevention of rockburst in metal mines-a case study of Sanshandao gold mine," Journal of Rock Mechanics and Geotechnical Engineering, vol. 8, no. 2, pp. 204-211, 2016.

[24] H. Wang, Y. Jiang, S. Xue et al., "Influence of fault slip on mining-induced pressure and optimization of roadway support design in fault-influenced zone," Journal of Rock Mechanics and Geotechnical Engineering, vol. 8, no. 5, pp. 660-671, 2016.

[25] Z. Li, L. Dou, W. Cai et al., "Fault-pillar induced rock burst mechanism of thick coal seam in deep mining," Chinese Journal of Rock Mechanics and Engineering, vol. 32, no. 2, pp. 333-342, 2013.

[26] N. Zhang, S. Zhao, Y. Zhao et al., "Mechanism of thrust fault rupture causing by unloading effect," Journal of China Coal Society, vol. 45, no. 5, pp. 1671-1680, 2020.
[27] P. L. Cai, L. Yang, and Z. Nong, "In-situ and experimental investigations of rockburst precursor and prevention induced by fault slip," International Journal of Rock Mechanics and Mining Sciences, vol. 108, pp. 86-95, 2018.

[28] L. Jiang, P. Kong, J. Shu, and K. Fan, "Numerical analysis of support designs based on a case study of a longwall entry," Rock Mechanics and Rock Engineering, vol. 52, no. 9, 2019.

[29] A. Sainoki and H. S. Mitri, "Influence of mining activities on the reactivation of a footwall fault," Arabian Journal of Geosciences, vol. 10, no. 5, 2017. 